Relations industrielles

Industrial Relations

\title{
Mémoires des groupements professionnels au Gouvernement provincial
}

\author{
III — L'Association Professionnelle des Industriels
}

Volume 9, numéro 2, mars 1954

URI : https://id.erudit.org/iderudit/1022900ar

DOI : https://doi.org/10.7202/1022900ar

Aller au sommaire du numéro

Éditeur(s)

Département des relations industrielles de l’Université Laval

\section{ISSN}

0034-379X (imprimé)

1703-8138 (numérique)

Découvrir la revue

\section{Citer ce document}

(1954). Mémoires des groupements professionnels au Gouvernement provincial : III - L'Association Professionnelle des Industriels. Relations industrielles / Industrial Relations, 9(2), 185-187.

https://doi.org/10.7202/1022900ar

Tous droits réservés @ Département des relations industrielles de l’Université Laval, 1954
Ce document est protégé par la loi sur le droit d'auteur. L'utilisation des services d'Érudit (y compris la reproduction) est assujettie à sa politique d'utilisation que vous pouvez consulter en ligne.

https://apropos.erudit.org/fr/usagers/politique-dutilisation/ 
Il est demandé au gouvernement d'amender cette loi afin que les taux des rémunérations aux arbitres soient rétablis comme dans le cas des arbitrages industriels et que les dépenses des arbitres soient à la charge du gouvernement plutôt qu'à celle des associations.

\section{5-Loi de l'aide à l'apprentissage}

Il est demandé au gouvernement d'amender la Loi de l'aide à l'apprentissage afin de prévoir qu'une demi-journée par semaine d'entraînement technique soit accordée à tous les apprentis, avec paye par l'employeur, durant toute leur période d'apprentissage.

Il est de plus demandé au gouvernement d'accorder son entier appui moral, et surtout financier à ces centres, en accordant à cette fin un budget supérieur au Ministère du Travail et au Ministère de la Santé et du Bien-être de la Jeunesse.

\section{6-Loi des établissements industriels}

Il est suggéré au gouvernement d'augmenter le nombre des inspecteurs et s'assurer que tous les établissements industriels observent la loi à la lettre.

Il est suggéré au gouvernement que le département responsable de l'octroi des permis temporaires de travail, fasse à tous les ans une revision des permis accordés pour le temps des vacances et que ces dits permis soient résiliés au moment de la rentrée des classes et à différents intervalles durant l'année scolaire afin que la Loi de la fréquentation scolaire obligatoire soit rigoureusement observée de sorte que les jeunes de moins de 16 ans continuent à fréquenter l'école.

\section{7-Loi des conventions collectives}

Il est demandé au gouvernement d'amender la loi de façon à obliger tout employeur qui embauche des ouvriers de quelque corps de métier que ce soit, alors que ces derniers ne détiennent pas un certificat de qualification, à payer une amende minimum adéquate, s'il est reconnu coupable.

Et également demandé une revision générale des cartes de compétence accordées jusquà date et l'uniformité de la carte de compétence à travers toute la province.

\section{8-Application du décret}

A l'heure actuelle les chantiers de moins de $\$ 25,000$ ne sont pas requis de payer les salaires stipulés par le décret couvrant les métiers de la construction. Il en résulte une injustice pour les employés de ces chantiers, et il est demandé an gouvernement que l'exemption de $\$ 25,000$ qui est ajoutée d'année en année par ie gouvernement dans la convention collective de travail, décret de Montréal et district, soit éliminée de ce décret.

\section{III-L'ASSOCIATION PROFESSIONNELLE DES INDUSTRIELS}

\section{Mémoire annuel présenté au Gouvernement de la province de Québec, le 8 février 1954.}

\section{1-Respect des organismes}

L'autorité, la compétence et l'impartialité des organismes, tels que, en particulier, les conseils ou tribunaux d'arbitrage, chargés d'appliquer la législation sociale, devraient être mieux affirmées et mieux établies. 
Pour qu'il en soit aînsí il faudrait tes faire participer à la dignité des tribunaux et au respect traditionnel dont ceux-ci sont l'objet.

\section{2-Commission de relations ouvrières}

La Commission de Relations Ouvrières, dans son application quotidienne de la loi des Relations Ouvrières, et dans l'exercice du pouvoir qui lui est donné de le faire, interprète cette loi, définit, précise et détermine des droits. En conséquence, ses actes, définitions et décisions, affectant gravement les droits, privilèges et responsabilités des employés et des employeurs, ont leur répercussion dans la société.

C'est pourquoi il est suggéré que toutes ses décisions soient motivées, de même que les dissidences quant à ces décisions, et qu'elles soient rendues publiques et aussi que cette commission use de ses droits et prérogatives pour formuler et publier des règles de pratique en toutes matières de sa compétence.

\section{3-Revision d'effectifs}

Il arrive, à l'occasion de certains conflits quant à la juridiction d'une organisation professionnelle et, aussi, dans certains cas de revision d'effectifs, que des ouvriers ne favorisent ni l'une ni l'autre des associations qui réclament le droit de représentation ou s'opposent à toutes espèces ou formes d'association.

La Commission devrait toujours déterminer la question soumise au vote de façon à permettre à tout employé d'exprimer son opinion et sa volonté sans avoir à choisir entre deux unions rivales. Ainsi serait respectée la liberté individuelle d'opinion, en même temps que l'obligation de voter, conformément à la loi des Relations ouvrières.

\section{4-Certificats d'agent négociateur périmés}

Il arrive fréquemment que des certificats d'agent négociateur accordés par la Commission de Relations Ouvrières ne sont pas utilisés et demeurent comme des armes aux mains d'organisateurs étrangers à l'entreprise concernée, même lorsque le syndicat certifié a cessé d'exister par la carence de membres.

Tout tel certificat dont, d'après les archives de la Commission, on se ne serait pas prévalu durant un an pour conclure ou renouveler un contrat de travail, devra être déclaré automatiquement annulé, pour cause de péremption, par la Commission de Relations Ouvrières.

\section{5-Certificat d'agent négociateur octroyé}

Il est suggéré qu'en ce qui concerne l'octroi d'un certificat d'agent négociateur, l'unité de négociation ne puisse, en aucun cas, dépasser les cadres de toute entreprise particulière; que, de plus, les certificats de reconnaissance soient désormais énumératifs et précis quant à l'étendue de la juridiction qu'ils confèrent, plutôt qu'exclusifs, en ce qui concerne les dispositions de l'article 6 de la loi des Relations Ouvrières.

\section{6-Conseils ou tribunaux d'arbitrage}

Il est notoire et constant que les conseils ou tribunaux d'arbitrage acquièrent une importance économique, sociale et juridique toujours grandissante et une influence marquante sur la formation et le régime de la législation du travail.

Il est suggéré qu'un système procédural régissant ces conseils soit édicté par le gouvernement de cette province, que ce système stipule des règles adéquates aux droits et intérêts impliqués et conformes à l'esprit juridique régnant dans notre province. 


\section{7-Mandat des conseils d'arbitrage}

Il est suggéré un amendement à la loi de façon à prescrire que, advenant un différend entre les parties sur la nature du mandat d'un conseil d'arbitrage, ou sur les matières soumises à l'appréciation et à la décision de celui-ci, ou sur l'étendue de sa juridiction, ce conseil soit compétent, en dernier ressort, à déterminer cette nature, ces matières et cette juridiction, après avoir entendu toutes et chacune des parties intéressées, en adoptant les normes ordinaires de la preuve, en jugeant suivant l'équité et la bonne conscience et en tenant compte des autres prescriptions de la loi.

\section{8-Fardeau de la preuve}

Le paragraphe 2 , de l'article 21 de la Loi des relations ouvrières impose au patron le fardeau de la preuve dans le cas d'un renvoi d'employé pour cause valable.

Le paragraphe premier du mème article protège complètement la liberté d'exercice du droit d'association.

Cette protection une fois assurée, le congédiement pour cause devient matière de droit ordinaire et la dérogation à ce droit que comporte les mots «dont la preuve lui incombe » ne paraît pas justifiée.

C'est pourquoi il est suggéré qu'il soit mis fin à cette dérogation injuste pour le patron, par la suppression des mots «dont la preuve lui incombe » à la fin du deuxième paragraphe de l'article 21 de la Loi des Relations Ouvrières.

\section{9-Vote de grève}

Il devrait ètre édicté que tenant compte des autres prescriptions de la loi, aucune grève ne pourra ètre déclarée ou déclenchée légalement sans qu'elle ait été décidée préalablement par la majorité des travailleurs liés à l'entreprise. Cette décision devra ètre prise par ces travailleurs, au scrutin secret, dans les quatorze jours qui suivront la connaissance donnée aux parties d'un rapport du conseil d'arbitrage sur le différend. Une réunion générale des employés concernés devra être convoquée à cette fin et tenue en présence de représentants de la Commission de Relations Ouvrières, à laquelle un exposé détaillé de la question sera fait, préalablement à la tenue du scrutin, par les dirigeants ouvriers et les représentants dı patronat. S'il n'est pas donné suite à un vote majoritaire favorable à la grève dans les huit jours qui suivront l'expiration du délai de quatorze jours mentionné ci-dessus, le droit de grève sera automatiquement périmé.

\section{0-Incorporation des syndicats}

Le système actuel qui confie au secrétariat provincial la faculté de constituer en corporation les associations professionnelles ou syndicats, prète à des abus et, tout au moins. présente des inconvénients sérieux.

Ne serait-il pas plus logique que cette matière de l'incorporation des associations professionnelles et des syndicats soit confiée à la juridiction du ministre du travai! qui devrait l'exercer dans les mêmes conditions que le fait actuellement le secrétaire provincial? 